\title{
Just the facts: drowning
}

\author{
David Jerome ${ }^{1,2,3}$ (1)
}

Received: 15 November 2021 / Accepted: 17 January 2022 / Published online: 7 February 2022

(c) The Author(s), under exclusive licence to Canadian Association of Emergency Physicians (CAEP)/ Association Canadienne de Médecine d'Urgence (ACMU) 2022

Keywords Drowning $\cdot$ Resuscitation $\cdot$ Wilderness

\section{Clinical scenario}

A 22-year-old male is brought into the emergency department (ED) by emergency medical services (EMS) following a witnessed drowning. The EMS crew has provided supplemental oxygen and started an IV. Upon arrival to the ED, the patient is alert and has a non-productive cough. He is tachycardic, tachypneic, hypertensive and normothermic. There are course rales heard across both lung fields. How should this patient be managed?

\section{Key clinical questions}

\section{What is the appropriate terminology to use when referring to patients who have drowned?}

The WHO's 2002 World Congress on Drowning defined drowning as "the process of experiencing respiratory impairment from submersion or immersion in liquid" [1]. An important implication of this definition is that drowning is not necessarily a fatal event. Any patient who presents with respiratory symptoms after an immersion or submersion event has "drowned."

Many terms which had previously been used to describe drownings are no longer appropriate. Terms which should no longer be used include near drowning, secondary drowning,

David Jerome

djerome@nosm.ca

1 Division of Clinical Sciences, Northern Ontario School of Medicine, Thunder Bay, ON, Canada

2 Department of Family Medicine, University of Alberta, Edmonton, ON, Canada

3 Canadian Association of Wilderness Medicine, Kelowna, BC, Canada wet drowning, dry drowning, active drowning, passive drowning, and silent drowning [2, 3].

\section{What is the pathophysiology of drowning?}

When water is aspirated, the initial response is a cough reflex. Significant aspiration may lead to laryngospasm. Unless the drowning event is aborted, cerebral hypoxia will lead to a loss of consciousness after approximately $1 \mathrm{~min}$. While the patient is unconscious a small amount of water enters the lungs causing direct cellular injury, hypoxic vasoconstriction and bronchospasm [2,3]. Surfactant washout leads to a noncardiogenic pulmonary edema. This edema can be so large in volume that it enters the upper airways where it can be directly visualized during resuscitation. During unconsciousness the swallowing reflex is intact and large volumes of water can enter the stomach, creating a vomiting risk during subsequent resuscitation efforts.

Drowning patients usually experience an initial sinus tachycardia, then as the cardiac tissues experience hypoxia the rhythm develops into bradycardia, pulseless electrical activity, and asystole. Ventricular fibrillation and pulseless ventricular tachycardia are rare [2].

\section{Can drowned patients be classified according to the severity of their symptoms?}

A Drowning Severity Classification System was developed by analyzing data from $>41,000$ rescues [4]. This system incorporates elements of the physical exam (pulse, respirations, blood pressure, and pulmonary auscultation) to classify drowning severity across 6 Grades (Table 1). This simple classification system provides a valuable tool for early and efficient assessment of drowning severity in either the pre-hospital or ED environments [3]. 
Table 1 Drowning Severity Classification System

\begin{tabular}{|c|c|c|c|}
\hline Grade & Associated Mortality & Signs and symptoms & Indicated interventions \\
\hline 1 & $0 \%$ & $\begin{array}{l}\text { - Cough } \\
\text {-BP maintained } \\
\text { - No rales on pulmonary auscultation } \\
\text { - No foam in the airway }\end{array}$ & $\begin{array}{l}\text { - Rest, warm and calm the victim } \\
\text { - External oxygen not indicated } \\
\text { - Assessment in ED not required }\end{array}$ \\
\hline 2 & $0.6-1.2 \%$ & $\begin{array}{l}\text { - Cough } \\
\text {-BP maintained } \\
\text { - Rales in some lung fields } \\
\text {-Small amount of foam in the airway }\end{array}$ & $\begin{array}{l}\text {-Apply } \mathrm{O} 2 \text { at } 5 \mathrm{~L} / \mathrm{min} \text { prehospital } \\
\text {-Assessment in ED required } \\
\text { - Obtain CXR and ABG }\end{array}$ \\
\hline 3 & $3.6-5.2 \%$ & $\begin{array}{l}\text { Acute pulmonary edema without hypotension } \\
\text {-Cough } \\
\text {-BP maintained } \\
\text { - Rales in all lung fields } \\
\text {-Large amount of foam in the airway }\end{array}$ & $\begin{array}{l}\text { - Apply } \mathrm{O} 2 \text { at } 15 \mathrm{~L} / \mathrm{min} \text { prehospital } \\
\text { - BiPap or mechanical ventilation with } \mathrm{PEEP} \text { and } \mathrm{FiO} 21.0 \text { until } \\
\text { ABG available } \\
\text {-ICU admission required }\end{array}$ \\
\hline 4 & $19.4-22 \%$ & $\begin{array}{l}\text { Acute pulmonary edema with hypotension } \\
\text {-Cough } \\
\text { - Hypotension } \\
\text { - Rales in all lung fields } \\
\text {-Large amount of foam in the airway }\end{array}$ & $\begin{array}{l}\text { - Grade } 3 \text { treatment } \\
\text {-IV crystalloids for maintenance of BP } \\
\text {-ICU admission required }\end{array}$ \\
\hline 5 & $31-44 \%$ & -Isolated respiratory arrest & -Initiate BLS \\
\hline 6 & $88-93 \%$ & -Cardiopulmonary arrest & $\begin{array}{l}\text {-Initiate ACLS with focus on effective ventilation and oxygena- } \\
\text { tion }\end{array}$ \\
\hline
\end{tabular}

If a patient presents with signs and symptoms that meet the criteria for multiple Grades, the patient should be classified to the highest applicable Grade level. For example, a hypotensive patient with cough and rales in all lung fields but no foam in the airway should be classified as a Grade 4 drowning. ED Emergency Department. Adapted from [4]

\section{What is the appropriate management of a patient who has drowned?}

All patients categorized as Grade 2-6 should be assessed in an ED. Grade 1 patients are asymptomatic, other than a mild cough which resolves within minutes, and they do not require any interventions.

The priority during resuscitation is ensuring effective oxygenation [2, 3]. Patients should receive oxygen at $\mathrm{FiO} 2$ 1.0 in the ED and may benefit from positive-pressure ventilation. Patients categorized as Grade 3-6 usually require mechanical ventilation; Grade 3 patients who are initially able to maintain oxygenation are likely to experience respiratory fatigue and require intubation. Intubated patients should be ventilated using a lung protective strategy, similar to patients with acute respiratory distress syndrome (ARDS) $[2,3]$.

Noncardiogenic pulmonary edema may be observed in the upper airway. Clinicians should not attempt to clear this edema from the upper airway because these efforts will be ineffective as the majority of the fluid is in the lower airways. Ineffective efforts to clear the upper airway will needlessly delay effective oxygenation which is the key to a successful resuscitation. Clinicians should manage noncardiogenic pulmonary edema in patients classified as Grade 3 and higher by providing positive-pressure ventilation [3]. If fluid was swallowed during the drowning event, however, patients are at high risk of vomiting and so clinicians should be prepared to manage vomitus in patients with a decreased level of consciousness [2].

Evaluation in the ED should include an arterial blood gas. There is no value in routine complete blood count or electrolyte studies. Historical teachings that patients who drowned experienced significant electrolyte and hematologic abnormalities have been disproven [2, 3]. Patients with a decreased level of consciousness should be evaluated for other pathology which may have led to the drowning event, such as hypoglycemia, myocardial infarction, and trauma. Hypothermia is common in drowning and, if present, needs to be treated alongside other resuscitation activities [2].

There is no evidence to support the use of empiric antibiotic therapy in patients who have drowned, and their use may cause harm $[2,3]$. There is no evidence of the value of diuretic use in patients who have drowned [2, 3]. Research is ongoing into the use of artificial surfactant and nitric oxide but their use is not currently routinely indicated [3].

\section{Should cervical spine (c-spine) precautions be employed in all drowned patients?}

The rate of c-spine injury during drownings was studied by Watson et al. [5]. Of the 2244 victims included in this 
review, only $11(0.5 \%)$ had a c-spine injury. Each victim with a c-spine injury had experienced a high-risk mechanism (e.g. diving, motorized watersport, airplane crash into water) and each had clinical evidence of serious injury.

A focus on unnecessary c-spine immobilization can distract clinicians from ensuring early effective oxygenation, and the application of a cervical collar can impede airway management $[2,5]$. C-spine immobilization should not be routinely applied to drowning victims, and should only be considered in patients with a history and exam suggestive of potential neurologic injury $[2,3]$.

\section{How long should a stable patient be observed in the emergency department after a drowning?}

Retrospective studies have shown that patients who have a delayed decompensation following a drowning nearly always deteriorate within $4 \mathrm{~h}$ of arrival to the ED. Patients with normalized respiratory function may be reasonably discharged from the ED following an observation period of 4-6 $\mathrm{h}$ [2].
Classification Scale. BiPap should be initiated, and the patient may require intubation if respiratory fatigue develops. The patient should be admitted to the ICU.

\section{References}

1. van Beeck EF, Branche CM, Szpilman D, Modell JH, Bierens JJ. A new definition of drowning: towards documentation and prevention of a global public health problem. Bull World Health Organ. 2005;83(11):853-6.

2. Schmidt AC, Sempsrott JR, Hawkins SC, Arastu AS, Cushing TA, Auerbach PS. Wilderness Medical Society practice guidelines for the prevention and treatment of drowning. Wilderness Environ Med. 2016;27(2):236-51.

3. Szpilman D, Morgan PJ. Management for the drowning patient. Chest. 2021;159(4):1473-83.

4. Szpilman D. Near-drowning and drowning classification: a proposal to stratify mortality based on the analysis of 1831 cases. Chest. 1997;112(3):660-5.

5. Watson RS, Cummings P, Quan L, Bratton S, Weiss NS. Cervical spine injuries among submersion victims. J Trauma. 2001;51(4):658-62.

\section{Case resolution}

This patient has signs of pulmonary edema including rales across all lung fields, but he is not hypotensive. He is therefore classified as a Grade 3 on the Drowning Severity 